\title{
Possibilities of Utilization Thermally Sprayed Coatings in the Field of Sink Rollers Renovation
}

\author{
Janette Brezinová1, Anna Guzanová1, , Pavlo Maruschak², Juraj Koncz' \\ 1 Technical University of Košice, Faculty of Mechanical Engineering, Mäsiarska 74, 04001 Košice, Slovakia \\ ${ }^{2}$ Ternopil Ivan Pulüj National Technical University, Ruska 56, 46001, Ternopil, Ukraine
}

\begin{abstract}
The paper deals with failure analysis of sink rollers used in hot-dip galvanizing of steel sheets. It presents the possibility of renovation the surface of the roller using thermally sprayed coatings. The paper contains results of research focused on quality evaluation of three coatings applied using HVOF technology - WC-Co, WC-NiMoCrFeCo and Co-MoCrSi. There was also investigated impact of sealing agent - boron nitride used for sealing the coating on corrosion rate of the coating. HVOF coatings were subjected to metallographic study with aim to study the structure, thickness, mechanical anchoring and hardness of coatings. There was also realised EDX analysis of chemical composition of coatings. Adhesion of coating was investigated in dependence of thermal cyclic loading. Main part of paper is focused on determining wear resistance of coatings by pin-on-disc in $1 \mathrm{M} \mathrm{NaCl}$ solution and corrosion rate by Tafel analysis. Experiment confirmed that sealing coating WC-Co with boron nitride improves corrosive resistance of the coating. The boron nitride seals the pores in the structure of coating and thus prevents the formation of corrosion and subsequent depreciation of coating in various corrosive environments. Based on reached results, coatings for renovation rollers surfaces can be recommended according to preferred priority. If corrosion resistance of rollers plays key role, WC-Co coating sealed with boron nitride can be recommended together with WC-NiMoCrFeCo coating and the Co-MoCrSi. If the main priority is wear resistance of roller, unsealed WC-Co coating or alloy CoMoCrSi coating can be used.
\end{abstract}

Keywords: Sink roller; renovation; thermal coating; HVOF technology; wear resistance.

\section{Introduction}

Galvanized steel sheets are strategic commodity used mainly in the automotive industry. The quality requirements for zinc coatings are high. It is very important to keep the thickness along entire width of the steel strip. Any disruption of homogeneity of the coating or presence of errors is unacceptable. The final quality of the zinc coating is given, among others, by the quality and purity of rollers submerged in molten zinc, around which the steel sheet during the plating is wrapped, Fig. 1.

Sink roller immersed in the molten zinc bath is affected by the dross is also attacked by the molten zinc leading to pitting and build-ups. All these factors affect the coil surface. Such rollers have very short life - up to two weeks. New sink rollers have no coatings on them. 


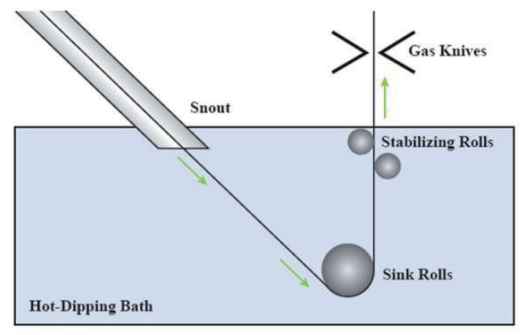

Fig. 1: Location of sink roller in the zinc bath.

To minimize costs, the damaged rollers are designed for renovation [1]. The most common way to extend the life of the rollers is the application of a coating containing hard WC particles using HVOF technology (High Velocity Oxygen Fuel) [24]. HVOF coatings are very hard metallic or hardmetallic particle binder functional coatings with very good corrosion and wear resistance [5-11]. The application of coatings containing WC can extend the service life of the roller up to 5 weeks. Damage or shorten the life of coated or uncoated sink rollers can occur in their production or renovation, during transport and storage as well as during operation.

The most common factors influencing the sink roller life:

In phase of production or renovation:

- Incorrect choice of roller material (deflection of the roller causing crack of applied coating),

- errors in base material (saizings, cracks, voids), Fig. 2,

- Incorrect or non-complied procedure of coating application technology, for example incorrect surface preparation, insufficient degreasing of the roller leading to peeling-off the coating, failure of the spraying device, the human factor,

- Improperly designed coating parameters (inappropriate roughness can cause dross build-ups) (Fig. 3),

- Improper roller geometry (circular runout of the roller, misalignment).

In phase of transport and storage:

- Exposure of sealed coating to moisture results in a map creation on the surface of the roller (Fig. 4).

During operation:

- Incorrect location of the roller in assembly (roller oscillation causes uneven wear of coating),

- Incorrect cleaning of roller in zinc bath (mechanical damage of coating - scratches),

- Incorrect realization of roller preheating before immersion to zinc bath (cracking of the coating),

- Frequently repeated preheating of the roller (ther- mal shock of the base material),

- Increased mechanical load (tension of steel sheet, wear of bearing), Fig. 5 ,

- Incorrect geometric properties of steel sheet,

- Incorrectly designed production program (frequent changes in production range).

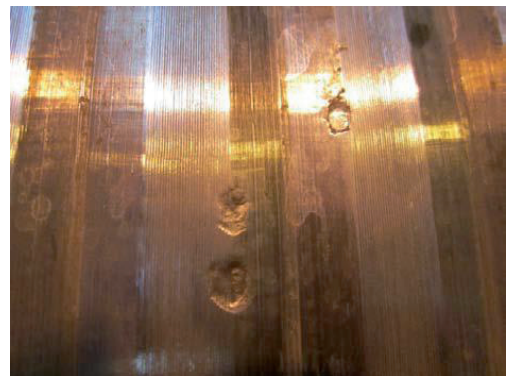

Fig. 2: Errors in base material.

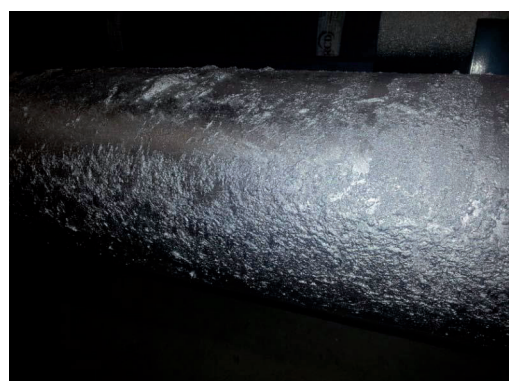

Fig. 3: Dross build-ups on the coating.

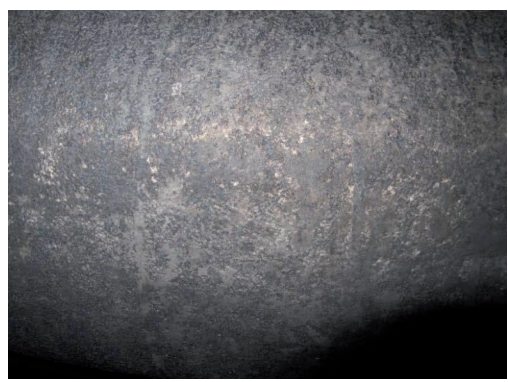

Fig. 4: Maps on the surface of the roller.

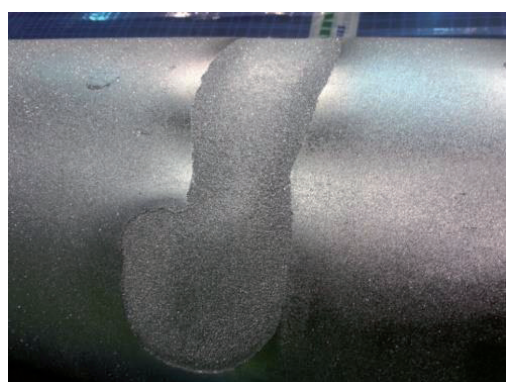

Fig. 5: Decohesion of the protective coating.

Coatings applied by HVOF technology are characterized by certain content of the porosity (1-2\%) [12]. Porosity of thermal spray coatings can 
lead to decreasing of their corrosion resistance in critical applications such as sink rolls in molten zinc. Sealing the thermally sprayed coatings can minimise their porosity to zero, therefore preventing the corrosive agents from penetrating to the substrate material. Sealing can either be done with different sealants, which are applied by painting onto the substrate, closing the open porosity of the coating surface, or by laser treatment. In laser treatment, a thin surface of the coating is melted and resolidified into a compact, homogeneous, nonporous layer. The morphology and composition of the laser treated cladding are transformed from the original sprayed structure. Applying sealing agent increases the cost of the coating, however, if the protective effect of the sealant is long enough, it can be economically applied for critical mechanical parts subject to corrosion.

The aim of this paper is to assess the possibility of using coatings WC-Co 88/12 (Amperit 512, Starck), WC-NiMoCrFeCo (Amperit 529, Starck) and CoMoCrSi (CO 109, Praxair) on renovation of rollers. Influence of sealing using boron nitride on corrosion resistance of the coating was demonstrated on WC-Co (Amperit 512.074) coating.

\section{Materials and Methods}

\subsection{Base material}

Studied coatings were applied on the base material of grade C15E. The test samples had a cylindrical shape with a diameter of $25 \mathrm{~mm}$ and a length of $50 \mathrm{~mm}$. Coating was applied on the base of the cylinder.

\subsection{Pretreatment of base material}

For cleaning, developing an appropriate microgeometry and enhancing adhesion of coatings by mechanical anchoring the base material was treated by abrasive blast cleaning. Used abrasive was white corundum with grain size of $0.7 \mathrm{~mm}$, air pressure $0.4 \mathrm{MPa}$, stand-off 300 $\mathrm{mm}$, impact angle of $90^{\circ}$.

\subsection{Powders used}

Characteristics of powder used are listed in Table 1.

Table 1: Characteristics of powders used.

\begin{tabular}{|c|c|c|c|}
\hline Powder & WC-Co & WC-NiMoCrFeCo & $\mathrm{Co}_{0} \mathrm{MoCrSi}$ \\
\hline Chemical/volume composition & $(88 / 12)$ & $(82 / 18)$ & $\begin{array}{l}\text { (Mo 28.5, Cr 8.5, Si 2.6, Co } \\
\text { rem) }\end{array}$ \\
\hline Particle type & $\begin{array}{l}\text { Agglomerated and sinte- } \\
\text { red low carbon (3.6 - } 4.1 \%)\end{array}$ & $\begin{array}{l}\text { Agglomerated and sin- } \\
\text { tered }\end{array}$ & Atomised \\
\hline Grain size in $\mu \mathrm{m}$ & $45 / 15$ & $45 / 15$ & $45 / 16$ \\
\hline Structure characteristics & Coarse WC & Medium WC & Intermetallic Laves phases \\
\hline Application data & $\begin{array}{c}\text { used for Zn bath rolls in } \\
\text { Continuous Galvanizing } \\
\text { Lines (CGL) }\end{array}$ & $\begin{array}{l}\text { alternative to WC-CoCr, } \\
\text { used for parts applied in } \\
\text { marine environments, } \\
\text { petrochemical and off- } \\
\text { shore applications }\end{array}$ & $\begin{array}{l}\text { excellent wear properties } \\
\text { from room temperature to } \\
816^{\circ} \mathrm{C} \text {, good hot hardness, } \\
\text { oxidation and corrosion } \\
\text { properties, low coefficient } \\
\text { of friction }\end{array}$ \\
\hline Appearance of the powder & & & \\
\hline
\end{tabular}

\subsection{Application of coatings}

Powders were sprayed by HVOF technology using spraying equipment TAFA JP 5000. Spraying parameters: nozzle -4 inch, Kerosene 22,7 I/h,
Oxygen $792 \mathrm{nl} / \mathrm{min}$, feed rate $75 \mathrm{~g} / \mathrm{min}$, stand-off $380 \mathrm{~mm}$.

\subsection{Method of coatings evaluation}

Structure, composition and thickness of the 
coating were studied on metallographic sections using SEM. The hardness of the coating was determined using test equipment Shimadzu HMV-2E with a load of $980.7 \mathrm{mN}$ (HV 0.1), hold time 15 seconds. The corrosion rate of the coating was determined by Tafel analysis using test device Potentiostat SP150.

The corrosion rate depends on the kinetics of both anodic (oxidation) and cathodic (reduction) reactions. According to Faraday's law, there is a linear relationship between the metal dissolution rate or corrosion rate, $i_{\text {corr }}(1)$ :

$$
R_{M}=\frac{M}{\eta F \rho} i_{c o r r}
$$

where $\mathrm{M}$ is the atomic weight of the metal, $\rho$ is the density, $\eta$ is the charge number which indicates the number of electrons exchanged in the dissolution reaction and $\mathrm{F}$ is the Faraday constant, $(96.485 \mathrm{C} / \mathrm{mol})$. The ratio $\mathrm{M} / \mathrm{n}$ is also sometimes referred to as equivalent weight.

Calculation of corrosion rates requires the determination of corrosion currents. When reaction mechanisms for the corrosion reaction are known, the corrosion currents can be calculated using Tafel Slope Analysis. The relationship between current density and potential of anodic and cathodic electrode reactions under charge transfer control is given by the Butler-Volmer equation (2), (3):

$$
\begin{aligned}
& i=i_{\text {corr }}\left(e^{2.303 \frac{\eta}{b_{a}}}-e^{2.303 \frac{\eta}{b_{c}}}\right) \\
& \eta=E-E_{\text {corr }}
\end{aligned}
$$

where $\mathrm{E}$ is the applied potential and $\mathrm{i}$ the measured current density. The overpotential, $\eta$, is defined as the difference between applied potential and the corrosion potential $\mathrm{E}_{\text {corr }}$. The corrosion potential, Ecorr is the open circuit potential of a corroding metal. The corrosion current, $\mathrm{i}_{\text {corr' }}$ and the Tafel constants $\mathrm{b}_{\mathrm{a}^{\prime}}$ and $\mathrm{b}_{\mathrm{c}}$ can be measured from the experimental data. For large anodic overpotentials $\left(\eta / b_{a}>>1\right)$ the Butler-Volmer equation simplifies to the Tafel equation for the anodic reaction (4):

$$
\eta=\log \left(i_{\text {corr }}\right)+b_{a} \cdot \log (i)
$$

Analogously, for large cathodic overpotentials $\left(\eta / b_{c}<<-1\right)$ the Tafel equation for the cathodic reaction is given by (5):

$$
\eta=\log \left(i_{\text {corr }}\right)+b_{c} \cdot \log |i|
$$

The Tafel equations predict a straight line for the variation of the logarithm of current density with potential.

Unsealed coatings were investigated under parameters (A) and sealed coating WC-Co under parameters for boron nitride (B). Tafel analysis was performed in $3.5 \% \mathrm{NaCl}$ solution. Used parameters are summarized in Table 2.

Table 2: Parameters used for Tafel analysis of the coating.

Parameters of Tafel analysis A B

\begin{tabular}{|l|l|l|}
\hline equivalent weight & $195.851 \mathrm{~g} / \mathrm{eq}$. & $24.820 \mathrm{~g} / \mathrm{eq}$. \\
\hline density & $15.630 \mathrm{~g} / \mathrm{cm}^{3}$ & $3.450 \mathrm{~g} / \mathrm{cm}^{3}$ \\
\hline surface area & $0.636 \mathrm{~cm}^{2}$ & $0.636 \mathrm{~cm}^{2}$ \\
\hline
\end{tabular}

Wear resistance of coatings was determined by pin-on-disk wear test. Parameters of test: normal load $1.5 \mathrm{~N}$, speed $0.02 \mathrm{~ms}^{-1}$, radius of wear track $11 \mathrm{~mm}$, static counterpart WC ball with a diameter of $6 \mathrm{~mm}$. Duration of test 1 hour, test couple immersed in $1 \mathrm{M} \mathrm{NaCl}$ solution.

\section{Results}

Microstructure and EDX analysis of evaluated coatings is shown in Fig. 6. The observed structure of the coatings is characteristic for thermal spraying coatings.

From Fig. 6 is clear that the coating WC-Co contains hard particles of WC surrounded by $\mathrm{Co}$ binding matrix. Size of WC particles is up to $5 \mu \mathrm{m}$ and they are evenly distributed in the Co matrix. EDX analysis confirmed the presence of the essential elements in the coating. A similar structure showed a coating WC-NiMoCrFeCo. The difference is only in the binding matrix which is an alloy of NiMoCrFeCo and in lower content of WC particles in the matrix compared to WC-Co coating. Coating Co-MoCrSi does not contain carbide phase, it consists of splats of CoMoCrSi alloy.

Average coating thickness and hardness HV0.1 was determined at metallographic sections, Fig. 7.

In Fig. 7 can be seen good mechanical anchoring of the coatings in profile of the roughened base material. Hardness of the base material is 168 HV 0.1, 

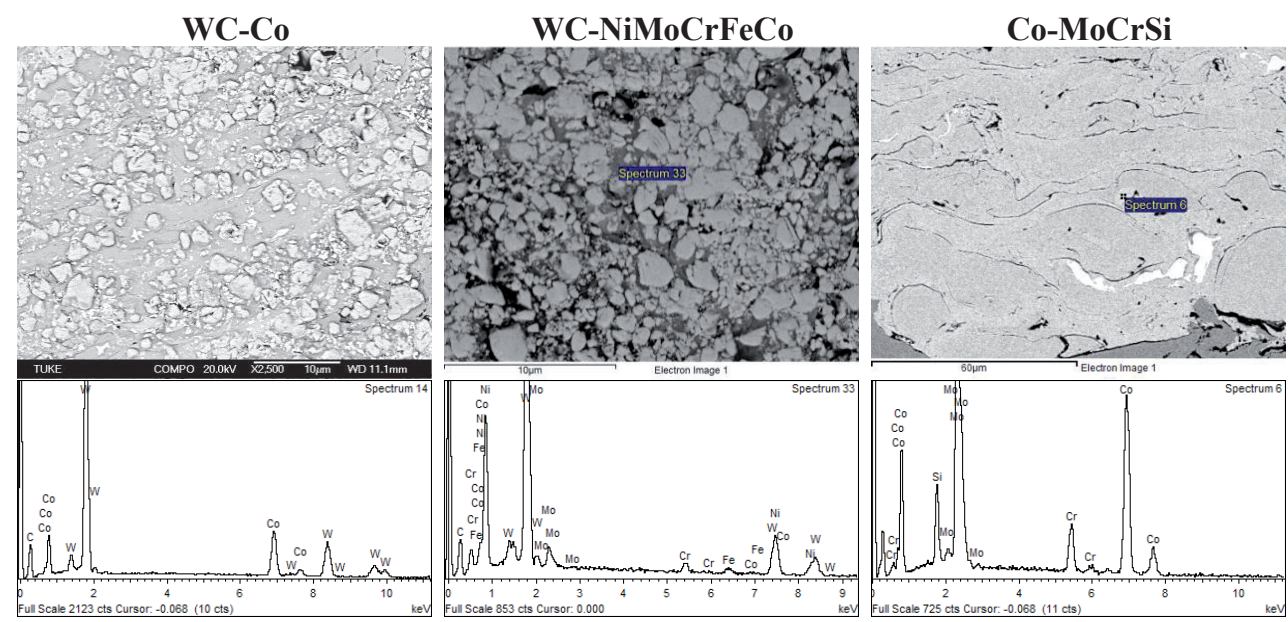

Fig. 6: Structure and EDX analysis of evaluated coatings.

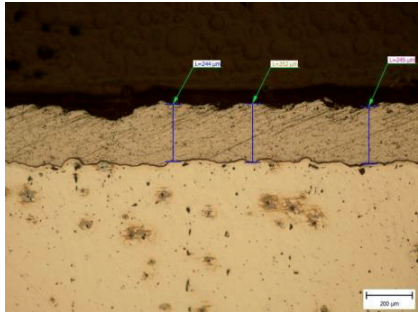

WC-Co, thickness $247 \mu \mathrm{m}$

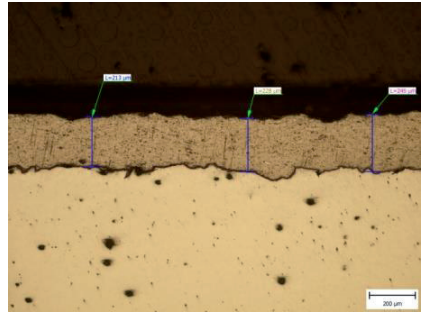

WC-NiMoCrFeCo, thickness $228 \mu \mathrm{m}$

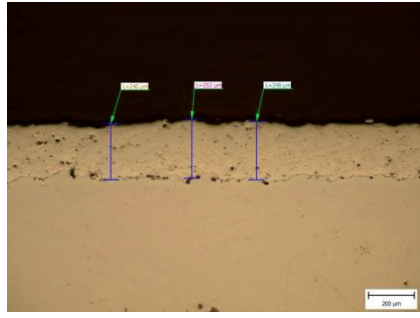

Co-MoCrSi, thickness $234 \mu \mathrm{m}$

Fig. 7: Metallographic sections and average thickness of coatings.

Table 3: Corrosion properties of coatings.

\begin{tabular}{|c|c|c|c|c|}
\hline & WC-Co & WC- $C_{0}+$ boron nitride & WC-NiMoCrFeCo & Co-MoCrSi \\
\hline (x) $\mathrm{E}_{\text {corr }}[\mathrm{mV}$ vs. Ref] & -740.117 & -697.775 & -381.235 & -508.283 \\
\hline$(\mathrm{x}) \mid[\mu \mathrm{A}]$ & 10.900 & 3.848 & 3.901 & 5.377 \\
\hline$(x) \beta c[m V]$ & 110.1 & 85.9 & 232.5 & 264.9 \\
\hline (x) $\beta \mathrm{a}[\mathrm{mV}]$ & 200.0 & 137.7 & 229.6 & 224.6 \\
\hline$\chi^{2}[-]$ & 69.7 & 2046.04 & 724.95 & 28.89 \\
\hline corr. rate $[\mathrm{mmpy}]$ & 0.70 & 0.14 & 0.25 & 0.35 \\
\hline
\end{tabular}

hardness of coatings is 1247 HV0.1 for WC-Co, 1230 HV 0.1 for WC-NiMoCrFeCo and 770 HV0.1for Co$\mathrm{MoCrSi}$. The presence of a high proportion of hard carbides WC in the coatings greatly increases their hardness.

Corrosion properties of coatings are listed in Table 3.

The highest corrosion rate was found for WCCo coating, corrosion rate of the WC-NiMoCrFeCo coating reached one third of WC-Co corrosion rate, and corrosion rate of alloy coating Co-MoCrSi reached half of WC-Co corrosion rate. Sealing of WCCo coating by boron nitride resulted in a significant reduction in corrosion rate of the coating (about $80 \%)$. It follows that the corrosion rate of coatings containing WC can be significantly affected in two ways: by chemical composition of the alloy binding phase, resulting recently in development of many new types of binding matrices and by sealing coatings using suitable sealing means. Corrosion 
rate of alloy coating Co-MoCrSi is comparable to WC-NiMoCrFeCo, and even does not contain carbide particles WC, contains most of chemical elements as those contained in the binding alloy phase of WC-NiMoCrFeCo coating.

The course of friction coefficient of coatings in the corrosive environment is shown in Fig. 8.
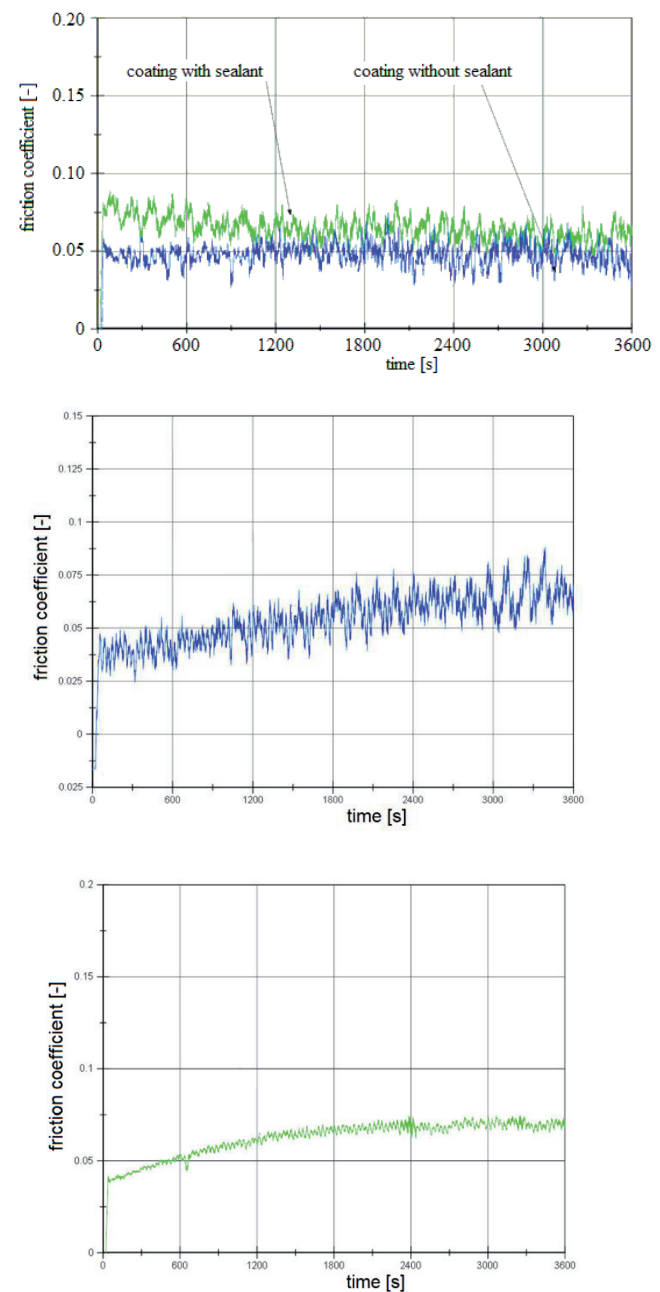

Fig. 8: Course of friction coefficient of WC-Co coating - sealed and unsealed (top), WC-NiMoCrFeCo (left) and Co-MoCrSi (right) coatings.

Obviously, the friction coefficient in all evaluated coatings after the initial running-in became stabilized at a value of 0.07 , for WC-Co coating after 20 minutes of the test (sealed and unsealed coating), for coating WC-Co-NiMoCrFeCo and CoMoCrSi after 40 min of the test. From Fig. 8 is also clear that friction coefficient of alloy coating CoMoCrSi was more stable throughout the tribological test compared to the friction coefficient of coatings containing WC particles that oscillated. Course and stabilization of friction coefficient is a result of reactions corrosive tribological system: coating static counterpart - test solution.

Mass losses of evaluated coatings are shown in Tab. 4.

Table 4: Mass loss of the base material and coatings.

\begin{tabular}{|l|c|}
\hline WC-Co unsealed & +0.0007 \\
\hline WC-Co sealed & -0.0062 \\
\hline WC-NiMoCrFeCo & -0.0269 \\
\hline Co-MoCrSi & -0.0011 \\
\hline
\end{tabular}

Wear track profile of base material and coatings shows Fig. 9.
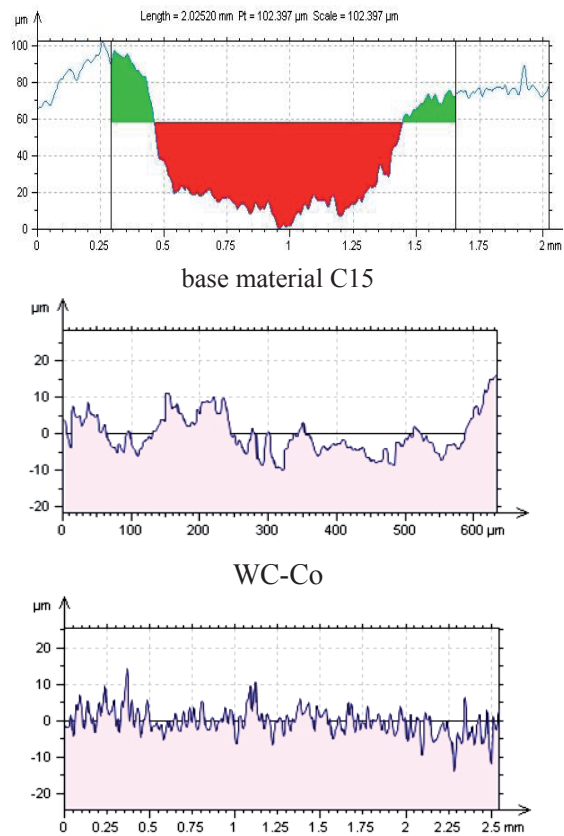

WC-NiMoCrFeCo

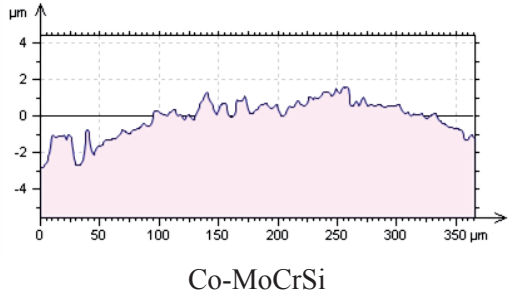

Fig. 9: Wear track profile of base material and coatings. 
Authors [13] visualized dependence of microstructure, properties and wear rate of the cermet coatings containing metallic binder phase in Fig. 10.

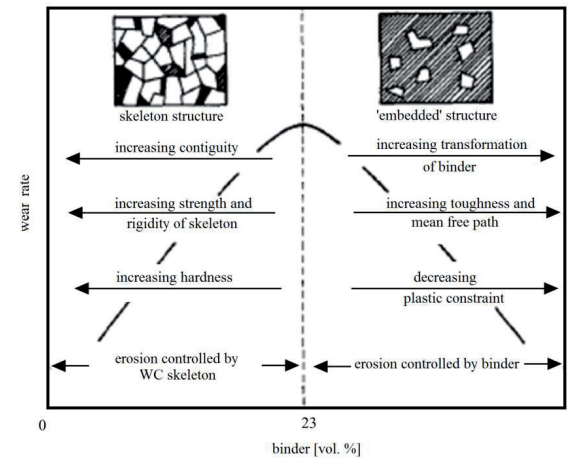

Fig. 10: Influence of content metal binding phase on structure, wear and mechanical properties of cermets for binder content up to 40 vol.\%.

Changing mechanical properties of cermet coatings is, according Fig. 10, the result of either intensification direct contacts of particles in WC skeleton (at a low content of binding matrix), or the result of increasing mean free path in matrix (at higher content of binding matrix). From Fig. 10 is also clear that the higher content of WC particles (lower content of binding matrix) is relating to higher wear resistance of coatings. Coating WCCo $(88 \%$ WC - 12\% Co) has a higher content of WC phase compared to WC-NiMoCrFeCo (82\% WC - 18\% NiMoCrFeCo). Wear resistance of WC-Co should be higher, according to Fig. 10, which was also confirmed by weight losses of coatings.

\section{Conclusion}

The paper presents results of research aimed at evaluation of structure and selected properties of three types of coatings - WC-Co, WC-NiMoCrFeCo and $\mathrm{Co}-\mathrm{MoCrSi}$, which are used for renovation of rollers immersed in zinc bath for galvanizing steel sheets. There was experimentally proved composition and structure of coatings, thickness, hardness, corrosion resistance and wear resistance in tribo-corrosive conditions. For comparison, WCCo coating was examined as sprayed, as well as sealed with boron nitride.

The structure of the coatings containing WC particles consists of hard WC carbide skeleton surrounded by binding matrix of $\mathrm{Co}$ or NiMoCrFeCo. Co-MoCrSi coating does not contain carbide particles, it consists of layered splats of CoMoCrSi alloy.

The thickness of WC-Co coating was $136 \mu \mathrm{m}$, WC-NiMoCrFeCo $228 \mu \mathrm{m}$ and the thickness of CoMoCrSi coating was $234 \mu \mathrm{m}$.

Coatings containing WC particles (WC-Co and WC-NiMoCrFeCo) showed hardness between 12301247 HV0.1, hardness of alloy coating Co-MoCrSi was $770 \mathrm{HV} 0.1$. All coatings represent the multiple increase in hardness compared to the hardness of the base material, which is $168 \mathrm{HV} 0.1$.

The lowest corrosion rate in $1 \mathrm{M} \mathrm{NaCl}$ solution showed WC-Co coating sealed with boron nitride (0.14 mmpy), followed by WC-NiMoCrFeCo $(0.25$ mmpy), Co-MoCrSi (0.35 mmpy) and the highest the corrosion rate was found in unsealed WC-Co coating (0.7 mmpy). The experimental works showed that the corrosion rate of WC containing coatings can be significantly affected by the chemical composition of the binding phase and by sealing coatings using appropriate sealing agents.

Adhesive wear of coatings was evaluated by friction coefficient and mass loss of evaluated coatings. The friction coefficient for all evaluated coatings after the initial running-on became stabilized at a value of 0.07 , indicating good sliding of coatings even in corrosive solution. The highest wear resistance was found in unsealed coating WCCo, followed by the Co-MoCrSi and WC-Co coating sealed with boron nitride. The maximum weight losses were observed in WC-NiMoCrFeCo, which is related to a lower content of WC particles in the coating matrix compared to WC-Co.

Based on results of realized tests, coatings for renovation rollers surfaces can be recommended according to preferred priority. If corrosion resistance of rollers plays key role, WC-Co coating sealed with boron nitride can be recommended together with WC-NiMoCrFeCo coating and the Co-MoCrSi. If the main priority is wear resistance of roller, unsealed WC-Co coating or alloy Co-MoCrSi coating can be used. For determination the suitability of particular HVOF coatings is necessary to consider also other factors as resistance of coating against abrasive wear, build-ups formation etc.

HVOF technology is a unique technology for the application of special alloys and composite coatings containing hard particles, which provides high resistant hard coatings with minimum porosity which ensures their high quality even in extreme 
tribo-corrosive conditions.

\section{Acknowledgments \\ This work was supported by the Slovak Research and Devel- opment Agency under the contract No. SK-UA-2013-0013, and Grant Scientific Project VEGA No. 1/0600/13.}

\section{References and Notes}

[1] Valentinelli, L., Valente, T., Casadei, F., Fedrizzi, L. (2004). Mechanical and tribocorrosion properties of HVOF sprayed WC-Co coatings. Corrosion Engineering Science and Technology, 39, 4, 301-307.

[2] Brezinová, J., Guzanová, A. (2012). Possibilities of utilization high velocity oxygen fuel (HVOF) coatings in conditions of thermal cyclic loading. Metalurgija, 51, 2, 211-215.

[3] Bobde, S.A., Kshirsagar, S.D. (2013). Improving the sink roll life in galvalume using material AT101 and the various thermal-spray coatings on SS316L roll surface. International Journal of Soft Computing and Engineering, 3, 1, 282-286.

[4] Guilemany, J.M., Miguel, J.M., Vizcaino, S., Climent, F. (2001). Rote of three-body abrasion wear in the sliding wear behaviour of WC-Co coatings obtained by thermal spraying. Surface and Coatings Technology, 140, 2, 141-146.

[5] Bunshah, R.F. (2001). Handbook of Hard Coatings: Deposition Technologies, Properties and Applications. Noyes publications / William Andrew Publishing, New York.

[6] Erickson, L.C., Hawthorne, H.M., Troczynski, T. (2001). Correlations between Microstructural Parameters, Micromechanical Properties and Wear Resistance of Plasma Sprayed Ceramic Coatings. Wear, 250, 1-12, 569-575.

[7] Wayne S.F., Sampath, S. (1992). Structure/Property Relationships in Sintered and Thermally Sprayed WC-Co. Journal of Thermal Spray Technology, 1, 4, 307-315.

[8] Singh, G., Bhandari, S. (2013). Slurry erosion behaviour of thermal sprayed Stellite- 6 and $\mathrm{Cr} 3 \mathrm{C} 2-25 \mathrm{NiCr}$ coatings. International Journal of Research in Mechanical Engineering and Technology, 3, 2, 94-101.

[9] Picas, J.A., Forn, A., Matthäus, G. (2006). HVOF coatings as an alternative to hard chrome for pistons and valves. Wear, 261 , 5-6, 477-484.

[10] Pennefather, R.C., Hankey, S.E., Hutchings, R., Ball, A. (1988). Recent Observations of the Erosion of Hard Materials. Materials Science and Engineering: A, 105-106, 2, 389-394.

[11] Yandouzi, M., Ajdelsztajn, L., Jodoin, B. (2008). WC-based composite coatings prepared by the pulsed gas dynamic spraying process: Effect of the feedstock powders, Surface and coatings technology, 202, 16, 3866-3877.

[12] Song, S.H., Xiao, P., Weng, L.Q. (2005). Evaluation of microstructural evolution in thermal barrier coatings during thermal cycling using impedance spectroscopy, Journal of the
European Ceramic Society, 25, 7, 1167-1173.

[13] Houdková, Š., Bláhová, O., Zahálka, F., Kašparová, M. (2012). The instrumented indentation study of HVOF-sprayed hardmetal coatings. Journal of Thermal Spray Technology, 21, 1 , 77-85.

\section{Biographical notes}

Janette Brezinová, prof. Ing. PhD., she received M.S. degree in Mechanical Technology from the Technical University of Košice in 1991, PhD. degree received in Mechanical Technology and Materials from the Technical University of Košice in 2003. She is Professor of Production Technology at the Department of Mechanical Technology and Materials of the Faculty of Mechanical Engineering, Technical University of Košice. Her research interests include optimization of finalizing treatment of engineering products, quality of surfaces and coatings, application of modern methods of corrosion monitoring, assessment of the properties of materials and coatings in tribological conditions, wear of materials and coatings, restoration technology.

Anna Guzanová, doc. Ing. PhD., she received M.S. degree in Mechanical Technology from the Technical University of Košice in 1997, PhD. degree received in Mechanical Technology and Materials from the Technical University of Košice in 2003. She is an associated professor of the Department of Mechanical Technology and Materials of the Faculty of Mechanical Engineering, Technical University of Košice. Her research interests include quality of surfaces and surface layers, mechanical and chemical pretreatment of technical surfaces, protective and functional coatings based on organic and inorganic materials.

Pavlo Maruschak, DrSc. prof., Ing, PhD., graduated from the Ternopil Ivan Puluj National Technical University, Faculty Food and Refine Industries in 2001. Position: Professor, Head of the Department of Industrial Automation. Specialization: diagnostic materials and structures, optical-digital systems, failure analysis, metallurgy equipment. He was written more than 300 publications (in English, Russian and Ukrainian languages) in the area of technical diagnostics, structural health monitoring, fracture mechanics and participated as a team member in several national and international projects.

Juraj Koncz, Ing., he received M.S. degree in Automotive Production from Technical University of Košice in 2013. Currently he is a Ph.D. student at the Department of Mechanical Technology and Materials of the Faculty of Mechanica Engineering, Technical University of Košice. His research interests include measurement corrosion properties of materials, layers and coatings based on metals and alloys. 